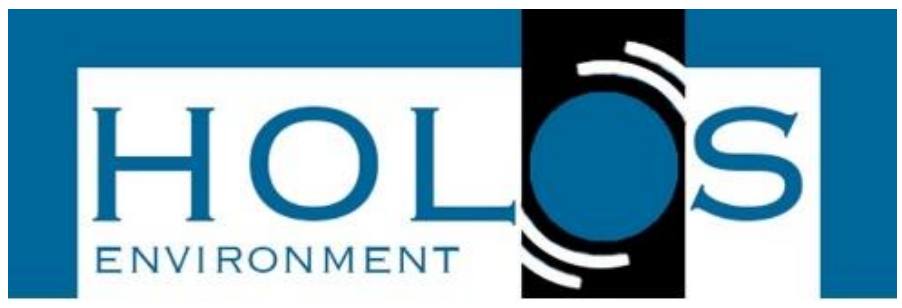

\title{
COMPARAÇÃO DA RETENÇÃO DE CÁDMIO E CHUMBO NOS TECIDOS VEGETAIS DAS MACRÓFITAS AQUÁTICAS AGUAPÉ (Eichhornia sp.) E TABOA (Typha sp.) POR BIOSSORÇÃO E FITORREMEDIAÇÃO
}

\author{
COMPARISON OF THE RETENTION OF CADMIUM AND LEAD IN PLANT \\ TISSUES OF AQUATIC MACROPHYTES WATER HYACINTH (Eichhornia sp.) \\ AND CATTAIL (Typha sp.) BY BIOSORPTION AND PHYTOREMEDIATION
}

\author{
Bruna Carolina Bartmeyer ${ }^{1}$; Luisa Helena dos Santos Oliveira'; \\ Lucia Helena Gomes Coelho ${ }^{1}$
}

Artigo recebido em: 23/05/2018 e aceito para publicação em: 06/05/2019.

DOI: http://dx.doi.org/10.14295/holos.v19i1.12295

\begin{abstract}
Resumo: Tecnologias alternativas como a biossorção e a fitorremediação são eficazes para remoção de metais da água. A fim de comparar essas duas tecnologias, em escala laboratorial, o presente trabalho teve como objetivo avaliar a retenção mássica dos metais tóxicos $\mathrm{Cd}$ e $\mathrm{Pb}$ nos tecidos vegetais de duas espécies de macrófitas aquáticas, o Aguapé (Eichhornia sp.) e a Taboa (Typha sp.). Na biossorção a biomassa seca das macrófitas aquáticas Eichhornia sp. e Typha sp. permaneceram em contato com soluções contaminadas com Cd $\left(4 \mathrm{mg} \mathrm{L}^{-1}\right)$ e $\mathrm{Pb}\left(4 \mathrm{mg} \mathrm{L}^{-1}\right)$ isolados em intervalos de tempo distintos, até 24 horas. As amostras foram coletadas, filtradas e analisadas por ICP OES. No ensaio de fitorremediação as plantas mães permaneceram em processo de aclimatação em solução nutritiva. Após a aclimatação plantas filhas foram coletadas e acondicionadas em frascos de polietileno com soluções nutritivas contaminadas com as mesmas concentrações de $\mathrm{Cd}$ e $\mathrm{Pb}$ isoladamente. Ao longo do período de ensaio, alíquotas da solução foram coletadas, filtradas e analisadas no ICP OES. Para verificação da concentração de metais acumulados nos tecidos vegetais, após 21 dias de contato com as soluções contaminadas, as plantas foram retiradas dos frascos, lavadas e secas para realização da digestão Nitro-Perclórica seguida da análise no ICP OES. Para ambos os tratamentos, os ensaios foram em triplicatas e para a análise estatística utilizou-se o ANOVA e o Teste-t, com nível de significância de $5 \%$. Os metais retidos nos tecidos vegetais $(q)$ do Aguapé apresentaram os valores máximos de $18,8 \mathrm{mg} \mathrm{g}^{-1}(\mathrm{Cd})$ e de $8,6 \mathrm{mg} \mathrm{g}^{-1}(\mathrm{~Pb})$ e a Taboa de $15,0 \mathrm{mg} \mathrm{g}^{-1}(\mathrm{Cd})$ e 4,6 $\mathrm{mg} \mathrm{g}^{-1}(\mathrm{~Pb})$ na biossorção. $\mathrm{Na}$ fitorremediação a concentração de metais nos tecidos vegetais do Aguapé foi de $3,2 \mathrm{mg} \mathrm{g}^{-1}$ (Cd) e $4,28 \mathrm{mg} \mathrm{g}^{-1}(\mathrm{~Pb})$ e de $5,0 \mathrm{mg} \mathrm{g}^{-1}(\mathrm{Cd})$ e 2,3 $\mathrm{mg} \mathrm{g}^{-1}(\mathrm{~Pb})$ na Taboa. Aparentemente, as biomassas secas apresentam um melhor desempenho na remoção de $\mathrm{Cd}$ e $\mathrm{Pb}$.
\end{abstract}

Palavras-chave: Biossorventes. Metais tóxicos. Tratamentos alternativos de água.

Abstract: Alternative technologies such as biosorption and phytoremediation are effective for removing metals form water. In order to compare these two technologies, in laboratory scale, the present work had as objective to evaluate the mass retention of the toxic metals $\mathrm{Cd}$ and $\mathrm{Pb}$ in the plant tissues of two species of aquatic macrophytes, Water hyacinth (Eichhornia sp.) and Cattail (Typha sp.). In the biosorption the dry biomass of aquatic macrophytes Eichhornia sp. and Typha sp. remained in contact with solutions contaminated with $\mathrm{Cd}\left(4 \mathrm{mg} \mathrm{L}^{-1}\right)$ and Lead $\left(4 \mathrm{mg} \mathrm{L}^{-1}\right)$ isolated at different time intervals, up to 24 hours. The samples were collected, filtered and analyzed by ICP OES. In the phytoremediation assay, the mother plants remained in acclimatization process in nutrient solution. After acclimatization, daughter plants were collected and conditioned in polyethylene bottles with nutrient solutions

\footnotetext{
${ }^{1}$ Universidade Federal do ABC (UFABC), Santo André, SP. E-mails: (bruna.bartmeyer@ufabc.edu.br, luisa.oliveira@ufabc.edu.br, lucia.coelho@ufabc.edu.br)
} 
contaminated with the same concentrations of $\mathrm{Cd}$ and $\mathrm{Pb}$ isolated. Throughout the test period, aliquots of the solution were collected, filtered and analyzed in ICP OES. To evaluate the concentration of metals accumulated in plants tissues, after 21 days of contact with contaminated solutions, the plants were removed from the flasks, washed and dried for Nitro-Perchloric digestion followed by ICP OES analysis. For both treatments, the tests were performed in triplicates and for the statistical analyzes, the ANOVA and the t-Test were used with a significance level of $5 \%$. The metals retained in plant tissues $(q)$ of Water hyacinth had the maximum values of $18.8 \mathrm{mg} \mathrm{g}^{-1}(\mathrm{Cd})$ and $8.6 \mathrm{mg} \mathrm{g}^{-1}(\mathrm{~Pb})$ and Cattail $15.0 \mathrm{mg}$ $\mathrm{g}^{-1}(\mathrm{Cd})$ and $4.6 \mathrm{mg} \mathrm{g}^{-1}(\mathrm{~Pb})$ in the biosorption. In the phytoremediation, the concentration of metals in plant tissues of Water hyacinth was $3.2 \mathrm{mg} \mathrm{g}^{-1}(\mathrm{Cd})$ and $4.28 \mathrm{mg} \mathrm{g}^{-1}(\mathrm{~Pb})$ and $5.0 \mathrm{mg} \mathrm{g}^{-1}(\mathrm{Cd})$ and 2.3 $\mathrm{mg} \mathrm{g}^{-1}(\mathrm{~Pb})$ in Cattail. Apparently, dry biomass exhibits better performance in $\mathrm{Cd}$ and $\mathrm{Pb}$ removal.

Palavras-chave: Alternative water treatments. Biosorbents. Toxic metals.

\section{INTRODUÇÃO}

A água é um recurso natural vital para todos os seres vivos e, apesar de sua importância, fatores como crescimento populacional desordenado, expansão rural e a industrialização são consideradas as principais fontes de degradação deste recurso (AZIMI et al., 2017).

Entre os diversos tipos de poluentes, os metais potencialmente tóxicos, apesar de serem constituintes naturais da crosta terrestre, têm se tornado danosos devido às ações humanas que alteraram os seus ciclos geoquímicos e o balanço bioquímico (RZYMSKI et al., 2015).

Os metais podem ser classificados como essenciais ou exclusivamente tóxicos para os seres vivos. Os primeiros são fundamentais, em pequenas quantidades, para a realização de processos biológicos, porém em excesso acabam se tornando prejudiciais, como o Ferro ( $\mathrm{Fe}$ ), Zinco ( $\mathrm{Zn})$, Cobre ( $\mathrm{Cu}$ ) e o Manganês $(\mathrm{Mn})$. Metais como o Cádmio ( $\mathrm{Cd}$ ), Chumbo (Pb), o metaloide Arsênio (As) e outros são considerados exclusivamente tóxicos, sendo estes associados à bioacumulação, a magnificação trófica e a persistência no ambiente, o que pode causar sérios problemas à saúde dos animais, como cânceres e disfunções nos órgãos e danos às plantas, por provocarem alterações fisiológicas podendo, tanto para animais como para as plantas, levar à morte (SRIVASTAVA e MAJUMDER, 2008; ALI, KHAN e SAJAD, 2013).

Apesar de existirem tecnologias capazes de remover os metais tóxicos da água, como a precipitação química, filtração com membranas, entre outras, o uso delas envolve grandes gastos com produtos químicos, energia elétrica e com o lodo de difícil disposição para descarte (MAHMOOD, MALIK e HUSSAIN, 2010). Além disso, existem fatores que interferem no processo de remoção dos metais de soluções, como o $\mathrm{pH}$, a temperatura, a própria concentração dos metais e presença de outras 
substâncias que podem atuar como seus retentores no meio por processos de absorção e adsorção (PARK, YUN e PARK, 2010).

A adsorção tem vantagens, frente às tecnologias citadas anteriormente, como: custos operacionais reduzidos, menor consumo de reagentes e o material adsorvente pode ser reutilizado, caso seja possível realizar o processo de dessorção ou de recuperação dos sítios ativos (FU e WANG, 2011).

O uso de materiais de origem biológica para fabricação de adsorventes recebe o prefixo "bio", indicando o envolvimento de um material biológico na sua concepção sendo, portanto, a biossorção um processo físico-químico que se enquadra nessa classificação. Nesse processo são utilizados, tipicamente, biossorventes provenientes da biomassa morta ou fragmentos de células e tecidos e os mecanismos de remoção incluem a adsorção, troca iônica e complexação com os sítios ativos das biomassas. Já a remoção de contaminantes utilizando seres vivos está relacionada ao acúmulo em seus tecidos (FOMINA e GADD, 2014) e, no caso do uso de plantas, este processo é denominado fitorremediação.

O processo de fitorremediação utiliza plantas vivas para a remoção de contaminantes da água e do solo. Entre as diversas plantas utilizadas, estão as macrófitas aquáticas, para o tratamento e/ou recuperação de superfícies alagadas. O Aguapé (Eichhornia sp.) e a Taboa (Typha sp.) são macrófitas aquáticas com as características necessárias para atuar como fitorremediadoras: apresentam um rápido crescimento, tem alta capacidade de absorver e acumular contaminantes do ambiente e são resistentes às variações no ambiente, como, temperatura e qualidade da água sendo, por isso, já utilizadas em alguns estudos e conhecidas pela capacidade fitorremediadora (MUFARREGE et al., 2014; REZANIA et al., 2015; STRUNGARU et al., 2015).

Para a remoção de metais, as plantas utilizam mecanismos físico-químicos, como adsorção, quelação, troca iônica e precipitação química e mecanismos biológicos como translocação para as partes aéreas, acúmulo no apoplasto ou no citoplasma celular e precipitação induzida pelos exsudatos das raízes ou pela atuação de microrganismos associados (MUFARREGE et al., 2014).

Além de atuarem no processo de fitorremediação, as biomassas secas do Aguapé e da Taboa também já foram estudadas, com sucesso, para atuar como material biossorvente (ABDEL-GHANI, HEGAZY e EL-CHAGHABY, 2009; SARASWAT e RAI, 2010; SHARAIN-LIEW, JOSEPH e HOW, 2011; PRIYA e SELVAN, 2017). 
Assim, processos que utilizam matérias-primas de origem natural são considerados tecnologias alternativas ou complementares reconhecidamente eficazes para a remoção de metais de soluções aquosas, como a biossorção e a fitorremediação (GOMES et al., 2016; KUMAR, SMITA e FLORES, 2017).

Posto isto, o presente trabalho visou comparar a retenção mássica de $\mathrm{Cd}$ e $\mathrm{Pb}$ nos tecidos vegetais das macrófitas Aguapé e a Taboa por tecnologias de biossorção e fitorremediação. Considerando-se a capacidade biossorvente e fitorremediadora das macrófitas aquáticas Aguapé e Taboa, esperou-se encontrar quantidade significativa de metais em seus tecidos vivos e/ou biomassa seca, reduzindo a concentração de metais tóxicos nas soluções testadas.

\section{MATERIAL E MÉTODOS}

A metodologia de trabalho foi dividida em duas etapas experimentais. Na primeira foram realizados os experimentos de biossorção de $\mathrm{Cd}$ e $\mathrm{Pb}$ em soluções aquosas utilizando a biomassa seca do Aguapé e da Taboa com a variação do tempo de contato. Na segunda realizou-se o ensaio de fitorremediação de soluções nutritivas contaminadas com $\mathrm{Cd}$ e $\mathrm{Pb}$ utilizando as macrófitas aquáticas Aguapé e Taboa e as análises da solução foram realizadas em diferentes tempos de contato.

As plantas utilizadas nos ensaios foram coletadas no Lago das Garças do Instituto de Botânica do Estado de São Paulo.

\subsection{Preparo dos reagentes}

Para o preparo das soluções foram utilizadas soluções padrão ácidas (matriz $\mathrm{HNO}_{3}$ a $5 \%$ ) de $1.000 \mathrm{mg} \mathrm{L}^{-1}$ de Nitrato de Cádmio $\left[\mathrm{Cd}\left(\mathrm{NO}_{3}\right)_{2}\right.$ ] e Nitrato de Chumbo $\left[\mathrm{Pb}\left(\mathrm{NO}_{3}\right)_{2}\right]$ da marca SpecSol ${ }^{\circledR}$ e diluídos em água deionizada. Foram preparadas soluções com a concentração inicial de $100 \mathrm{mg} \mathrm{L}^{-1}$ para ser diluída e usada em seguida, para o preparo de soluções com a concentração de $4 \mathrm{mg} \mathrm{L}^{-1}$ de cada metal.

$\mathrm{O}$ pH de cada solução foi ajustado para 5,0 a 5,3 por meio da adição de solução de $\mathrm{NaOH}$ com a concentração de $1,0 \mathrm{~mol} \mathrm{~L}^{-1}$. Antes de iniciar os experimentos, toda a vidraria utilizada foi lavada e descontaminada com $\mathrm{HNO}_{3}$ a $10 \%(\mathrm{v} / \mathrm{v})$. A solução nutritiva para as plantas, utilizada para os ensaios de fitorremediação, foi a de 
Hoagland e Arnon a 30\%, (v/v), sendo preparada de acordo com o procedimento dos próprios autores (HOAGLAND e ARNON, 1950).

\subsection{Biossorção}

Para o preparo das biomassas secas, após a coleta, as plantas foram lavadas com água corrente para remoção de solo e sedimentos aderidos à superfície das plantas, secaram naturalmente por 10 dias, seguidas de secagem em estufa a $70{ }^{\circ} \mathrm{C}$ por 48 horas (ABDEL-GHANI, HEGAZY e EL-CHAGHABY, 2009; FAWZY et al., 2016). Após a secagem, as plantas foram trituradas em moinho de facas e as biomassas peneiradas. O material utilizado para os experimentos ficou retido entre as malhas de $>0,25 \mathrm{~mm}$ e <0,30 $\mathrm{mm}$. Antes do início de cada experimento, as biomassas foram acondicionadas em cápsulas de porcelana e secas em estufa a $100^{\circ} \mathrm{C}$ por 1 hora para remoção da umidade.

Em cada Erlenmeyer de $100 \mathrm{~mL}$ foi adicionado $50 \mathrm{mg}$ de biomassa seca de cada planta, em seguida, $20 \mathrm{~mL}$ da solução de $4 \mathrm{mg} \mathrm{L}^{-1}$ de cada metal separadamente. Os Erlenmeyers foram vedados com plástico PVC e colocados na mesa agitadora com temperatura ambiente monitorada de, em média, $25 \pm 2{ }^{\circ} \mathrm{C}$ e rotação de $100 \mathrm{rpm}$. Os controles foram realizados com as mesmas soluções sem a adição das biomassas secas e os experimentos foram realizados em triplicata $(n=3)$ para garantir a confiabilidade analítica dos resultados obtidos.

Os intervalos de tempo de realização dos ensaios foram: 0 (concentração inicial), $15 \mathrm{~min}, 30 \mathrm{~min}, 60 \mathrm{~min}$ (1 hora), $120 \mathrm{~min}$ (2 horas), $240 \mathrm{~min}$ (4 horas), $480 \mathrm{~min}$ (8 horas), 720 min (12 horas) e 1440 min (24 horas). Após o término dos tempos estabelecidos, as soluções foram filtradas, armazenadas em tubos do tipo Falcon e analisadas no Espectrômetro Óptico de Emissão Atômica com Plasma Indutivamente Acoplado (ICP OES) da Central Experimental Multiusuários da UFABC.

Para certificação de que as plantas utilizadas nos ensaios não estavam inicialmente contaminadas com $\mathrm{Cd}$ ou $\mathrm{Pb}$, amostras das plantas in natura (sem contato com os metais) foram digeridas por meio da digestão Nitro-Perclórica, conforme procedimento realizado por Tavares, Oliveira e Salgado (2013). 


\subsection{Fitorremediação}

Para os ensaios de fitorremediação, após a coleta, foi realizada uma limpeza prévia para remoção de fragmentos mortos e seleção das plantas quanto à uniformidade e tamanho, além disso, as Taboas tiveram a porção superior de suas folhas podadas. Em seguida, as plantas foram lavadas com água corrente para remoção de sedimentos e materiais aderidos nas folhas e raízes, lavadas por 1 minuto em solução de hipoclorito de sódio $1 \%(\mathrm{v} / \mathrm{v})$ e enxaguadas novamente em água corrente e em água de osmose reversa (OLIVEIRA et al., 2001). Após as lavagens, as plantas foram encaminhadas para aclimatação na casa de vegetação localizada no campus de São Bernardo da UFABC, sendo acondicionadas em recipientes de polietileno com $5 \mathrm{~L}$ de solução nutritiva de Hoagland e Arnon a $30 \%$ (v/v) (DAS, GOSWAMI e DAS TALUKDAR, 2016; OLIVEIRA et al., 2018), pH na faixa de 5,0 a 6,0, temperatura de $25 \pm 2 \stackrel{\circ}{ } \mathrm{C}$ e fotoperíodo de 12 horas. As plantas ficaram em período de aclimatação por 21 dias e a reposição da água perdida por evapotranspiração ocorreu a cada dois dias.

Após o período de aclimatação, foram selecionadas plantas filhas do Aguapé e da Taboa com tamanhos e pesos semelhantes. Três plantas de cada tipo foram separadas para realização da digestão nitro-perclórica visando à verificação de possível contaminação inicial de $\mathrm{Cd}$ e $\mathrm{Pb}$.

Cada planta filha foi introduzida em frascos de polietileno com $5 \mathrm{~L}$ de solução nutritiva de Hoagland e Arnon a 30\% (v/v) contendo $4 \mathrm{mg} \mathrm{L}^{-1}$ das soluções ácidas de $\mathrm{Cd}\left(\mathrm{NO}_{3}\right)_{2}$ e $4 \mathrm{mg} \mathrm{L}^{-1}$ de $\mathrm{Pb}\left(\mathrm{NO}_{3}\right)_{2}$, separadamente, e acompanhadas por até 21 dias (DAS, GOSWAMI e DAS TALUKDAR, 2016). O pH da solução foi ajustado para 5,0 a 5,3 pela adição de solução de $\mathrm{NaOH}$ com a concentração de $1,0 \mathrm{~mol} \mathrm{~L}^{-1}$. Para verificar a concentração dos metais da solução, alíquotas eram retiradas em intervalos de tempo regulares, filtradas e analisadas no ICP OES. A cada dois dias completava-se a água dos frascos para compensar as perdas por evapotranspiração. Os experimentos foram realizados em triplicatas $(n=3)$ para garantir a confiabilidade analítica dos resultados e os controles foram realizados com a solução nutritiva contendo os metais e sem a inserção das plantas.

Ao término do experimento, as plantas foram recolhidas e enxaguadas com água de osmose reversa para remoção de possíveis metais acumulados de maneira superficial. As plantas contaminadas e as separadas inicialmente, para verificar a 
possível contaminação inicial por $\mathrm{Cd}$ e $\mathrm{Pb}$, foram secas naturalmente inteiras e posteriormente permaneceram em estufa por $48 \mathrm{hr}$ a $70 \stackrel{\circ}{ } \mathrm{C}$. Após a secagem, foram pesadas, trituradas seguida da digestão Nitro-Perclórica.

\subsection{Condições do Espectrômetro Óptico de Emissão Atômica com Plasma Indu- tivamente Acoplado (ICP OES)}

O comprimento de onda utilizado para a leitura do Cd foi de $214,439 \mathrm{~nm}$ e para o Pb de 220,353 nm. A elaboração das curvas de calibração do equipamento seguiram as seguintes concentrações de cada metal em conjunto $0 \mathrm{mg} \mathrm{L}^{-1}$ (branco), 0,25 mg L1, 0,50 mg L-1, 1,00 mg L-1, 2,50 mg L-1 e 5,00 mg L-1.

De acordo com a literatura, os limites aproximados de detecção (LD) do ICP OES são de $0,004 \mathrm{mg} \mathrm{L}^{-1}$ para o $\mathrm{Cd}$ e de $0,04 \mathrm{mg} \mathrm{L}^{-1}$ para o $\mathrm{Pb}$ (APHA, 2012) e os limites de quantificação (LQ) podem ser considerados 3,3 vezes os valores dos LDs, sendo, portanto de $0,0132 \mathrm{mg} \mathrm{L}^{-1}$ para o $\mathrm{Cd}$ e de $0,132 \mathrm{mg} \mathrm{L}^{-1}$ para o $\mathrm{Pb}$ (WENZL et al., 2016).

\subsection{Análise dos resultados}

Para o cálculo das médias aritméticas foram desconsideradas replicatas com diferença maior que $20 \%$ em relação às outras. Todos os resultados apresentados foram comparados com valores obtidos a partir dos resultados das médias aritméticas dos controles e os resultados nos gráficos representam as remoções obtidas pelas tecnologias de biossorção e fitorremediação em porcentagem.

Todos os cálculos para a elaboração dos gráficos e as análises estatísticas (ANOVA e o Teste-t,) foram realizados com o software Excel. Com a análise ANOVA foi possível verificar se há diferenças estatisticamente significativas entre as amostras analisadas e o Teste-t foi realizado para validação. O nível de significância adotado foi de $5 \%$.

\subsection{Cálculo da capacidade de adsorção dos tecidos vegetais}

A capacidade de adsorção, que é a capacidade do biossorvente em reter os metais, foi calculada utilizando a seguinte equação (FAWZY et al., 2016): 


$$
q=\frac{(C i-C f) x V}{w}
$$

Onde $q$ é a quantidade do metal adsorvido por unidade de biossorvente ( $\mathrm{mg} \mathrm{g}^{-}$ $\left.{ }^{1}\right), V$ é o volume da solução (L) e $w$ é a massa do biossorvente utilizado (g). A subtração ( $C i-C f)$ resulta na concentração de metal retido na biomassa, sendo esta subtração utilizada para o ensaio de biossorção. Como no ensaio de fitorremediação foi realizada a digestão do tecido vegetal, a concentração utilizada para o cálculo do $q$ foi obtida pela leitura no ICP OES. A partir do resultado desta equação é possível comparar as duas técnicas de remoção de metais em mg de metal por grama de biomassa.

\section{RESULTADOS E DISCUSSÃO}

Os coeficientes de correlação $\left(R^{2}\right)$ do Cádmio e do Chumbo obtidos por meio das leituras no ICP OES, foram de 0,998 e 0,991, respectivamente.

O cálculo do $q$ evidencia a quantidade de metal que ficou retido na biomassa da planta. Nas Figuras 1 e 2 são apresentados os valores de $q$ para $\mathrm{Cd}$ e Pb retidos nas biomassas secas de Aguapé e Taboa de acordo com os tempos de contato.

Figura 1 - Concentração de Cd (mg de metal por grama de biomassa) nas biomassas secas de Aguapé e Taboa em diferentes tempos de contato $(n=3)$

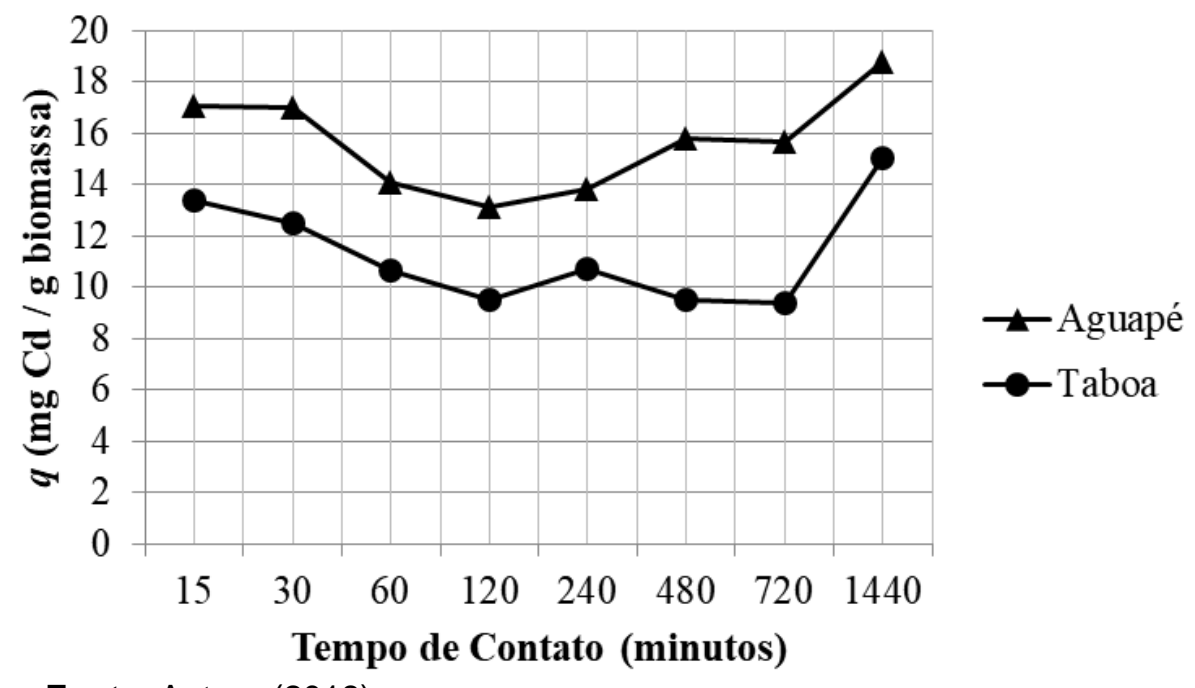

Fonte: Autora (2018) 
Figura 2 - Concentração de $\mathrm{Pb}$ (mg de metal por grama de biomassa) nas biomassas secas de Aguapé e Taboa em diferentes tempos de contato $(n=3)$.

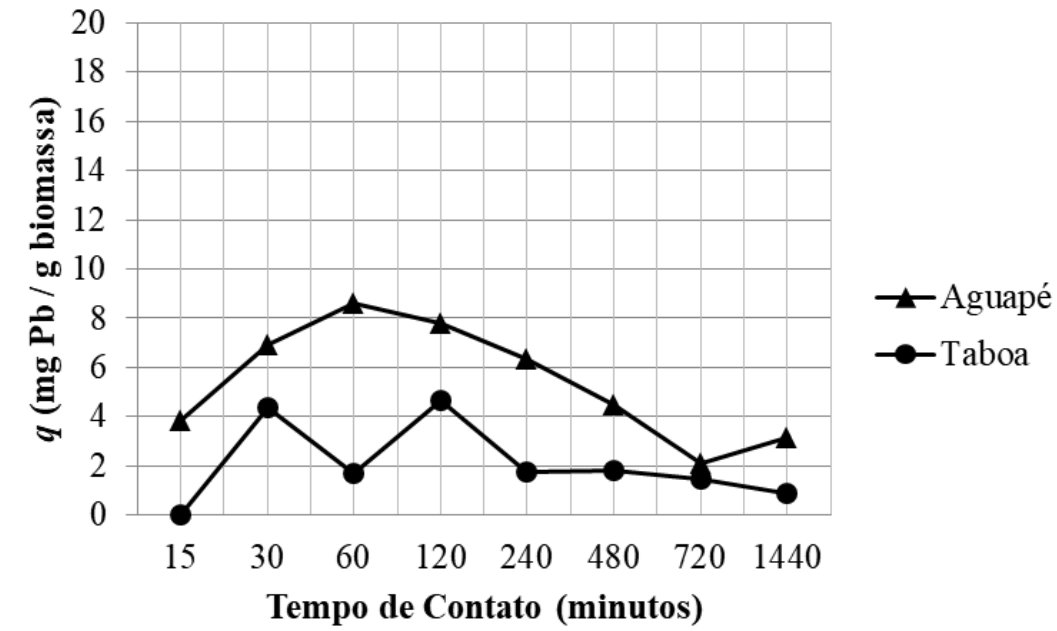

Fonte: Autora (2018)

Para o Aguapé o q máximo foi obtido no tempo de contato de 1440 min com valor de 18,81 mg de Cd por g de biomassa e o valor mínimo de 13,13 $\mathrm{mg} \mathrm{g}^{-1}$ no tempo de 120 min. Para a Taboa, o valor máximo também ocorreu no tempo de contato de 1440 min, já o mínimo ocorreu aos 720 min de ensaio com os valores de 15,06 mg g${ }^{1}$ e $9,41 \mathrm{mg} \mathrm{g}^{-1}$, respectivamente.

Em relação ao $\mathrm{Pb}$, o q máximo para o Aguapé ocorreu aos 60 min com valor de 8,60 mg g- ${ }^{-1}$ e o mínimo aos 720 min com retenção de 2,09 $\mathrm{mg} \mathrm{g}^{-1}$. Para a Taboa a retenção máxima foi de 4,66 $\mathrm{mg} \mathrm{g}^{-1}$ aos 120 min e a mínima (desconsiderando o tempo de $15 \mathrm{~min}$, onde não houve retenção) de $0,90 \mathrm{mg} \mathrm{g}^{-1} \mathrm{com} 1440 \mathrm{~min}$ de ensaio.

Estudos utilizando a biomassa seca de Eichhornia crassipes e Typha sp. para remoção de $\mathrm{Cd}$ e $\mathrm{Pb}$ de soluções aquosas, indicaram que os metais são removidos por reações de troca iônica, pela liberação dos cátions $\mathrm{Ca}^{2+}, \mathrm{Mg}^{2+}, \mathrm{K}^{+}$e $\mathrm{Na}^{+}$e complexação superficial com grupos contendo oxigênio, como carboxila (-COOH), hidroxila $(-\mathrm{OH})$, alcanos $(-\mathrm{C}-\mathrm{H})$, amino $\left(-\mathrm{NH}_{2}\right)$ e carbonila $(-\mathrm{C}=\mathrm{O})$, precipitação ou co-precipitação na superfície da biomassa nas formas de $\mathrm{CdCO}_{3}, \mathrm{Cd}_{3}\left(\mathrm{PO}_{4}\right)_{2} \mathrm{e} \mathrm{Cd}(\mathrm{OH})_{2}$, entre outras e sorção eletrostática entre o Cd e pares de elétrons disponíveis na superfície das biomassas (LIU et al., 2011; IBRAHIM et al., 2012; ZHANG et al., 2015; FAWZY et al., 2016). Além dos mecanismos acima citados, a rugosidade e a presença de poros na superfície das biomassas também favorecem a sorção de metais (FAWZY et al., 2016; ZHENG et al., 2016). Por meio destes estudos, fica evidente que os 
mecanismos de remoção de $\mathrm{Cd}$ e $\mathrm{Pb}$ de soluções aquosas pelas biomassas secas das plantas são variados e dependem muito da constituição da superfície da biomassa.

Para a fitorremediação, os valores de $q$ foram calculados ao término dos 21 dias de ensaio. A concentração de $\mathrm{Cd}$ na biomassa do Aguapé foi de $3,22 \mathrm{mg} \mathrm{g}^{-1}$ e de 5,00 $\mathrm{mg} \mathrm{g}^{-1}$ na Taboa. Para o Pb foi de 4,28 $\mathrm{mg} \mathrm{g}^{-1}$ no Aguapé e 2,39 $\mathrm{mg} \mathrm{g}^{-1}$ na Taboa.

O acúmulo preferencial de metais nas raízes do Aguapé e da Taboa ocorre pelo processo de precipitação e co-precipitação realizada pela ação de microrganismos que se propagam em sua rizosfera e são responsáveis pela imobilização e remoção dos metais por essas plantas (SYUKOR et al., 2016). Além disso, para Typha sp., o acúmulo de metais em suas raízes está relacionado às barreiras protetoras (apoplastos) presentes nas raízes que impedem o transporte dos poluentes para os tecidos fotossintéticos (LYUBENOVA et al., 2012; OLIVEIRA et al., 2018).

Além da ação dos microrganismos e da barreira protetora, outra forma está sendo relacionada à tolerância das plantas e acúmulo dos metais. A parede celular das células das raízes mantém um contato direto com os metais tóxicos ligando-se a eles. Essa ligação ocorre devido à presença de microporos carregados negativamente com grupos carboxílicos em sua estrutura e funcionam como locais de ligação e troca de cátions (RODRIGUES et al., 2016). Estes microporos existem dentro de uma rede composta de celulose, hemicelulose, pectinas e glicoproteínas sendo, muitas delas, carregadas negativamente em razão da presença dos grupos carboxílicos que atuam como sítios de ligação catiônica o que promove a absorção de metais pelas plantas pela captação passiva. Metais potencialmente tóxicos são preferencialmente atraídos e ligados a esses sítios de troca iônica que existem no córtex das paredes celulares das raízes (SINGH, RICHA e ARCHANA, 2011). Além da adsorção, ocorre a absorção dos metais (o transporte para o interior das células vegetais) que é responsável por outro estágio de remoção de metais de uma solução (LI et al., 2016). Assim como para a biossorção, as características físico-químicas da superfície das plantas influenciam o processo de remoção de metais tóxicos, ademais, os microrganismos associados às raízes das plantas contribuem para esse processo.

A Tabela 1 apresenta os dados quantitativos de metais acumulados nas biomassas das plantas após os ensaios de biossorção e fitorremediação. 
Tabela 1 - Comparação das retenções mássicas máximas de Cd e Pb por $\mathrm{g}$ de biomassa de Aguapé e Taboa

\begin{tabular}{|c|c|c|c|c|}
\hline \multirow[b]{2}{*}{$q$} & \multicolumn{2}{|c|}{ Biossorção (mg g $\left.{ }^{-1}\right)$} & \multicolumn{2}{|c|}{ Fitorremediação $\left(\mathrm{mg} \mathrm{g}^{-1}\right)$} \\
\hline & Cd & $\mathrm{Pb}$ & Cd & $\mathrm{Pb}$ \\
\hline Aguapé & 18,81 & 8,60 & 3,22 & 4,28 \\
\hline Taboa & 15,06 & 4,66 & 5,00 & 2,39 \\
\hline
\end{tabular}

Fonte: Autora (2018)

Ao comparar os resultados, percebe-se que os ensaios conduzidos pelo processo de biossorção, apresentaram maior eficiência do que os realizados pela tecnologia de fitorremediação. Com relação ao Aguapé e o $\mathrm{Cd}$, a retenção pela biossorção foi 5,8 vezes maior que a fitorremediação, já para a Taboa e o Cd a relação foi 3,0 vezes maior. Com relação ao $\mathrm{Pb}$, para o Aguapé a retenção pela biossorção foi 2 vezes maior e para a Taboa, 1,9 vezes maior que a da fitorremediação.

O ensaio de biossorção, realizado em escala laboratorial, foi realizado em água pura, ou seja, sem a presença de outras espécies iônicas para competir com os íons $\mathrm{Cd}$ e $\mathrm{Pb}$. $\mathrm{O}$ fato de que outros íons na solução afetam a remoção de metais, por exemplo, foi estudado por Murithi et al. (2014). Estes pesquisadores estudaram os efeitos dos íons de $\mathrm{Na}, \mathrm{K}, \mathrm{Mg}$ e Ca no processo de adsorção de Cd pela biomassa seca de Eichhornia crassipes. Seus resultados indicaram que a capacidade de adsorção da biomassa seca foi reduzida sendo que a presença de $\mathrm{Mg}$ e Ca reduziram em mais de $50 \%$ a capacidade de adsorção do $\mathrm{Cd}$, provavelmente relacionada à competição pelos sítios de ligação.

No estudo de Mahamadi e Nharingo (2010) foi avaliada a competição no processo de adsorção entre os íons $\mathrm{Pb}, \mathrm{Cd}$ e Zn pela biomassa seca de Eichhornia crassipes. Seus resultados indicaram uma capacidade de adsorção do $\mathrm{Pb}$ de 24,01 mg g${ }^{1}$ e de $9,92 \mathrm{mg} \mathrm{g}^{-1}$ de Cd. Além disso, quando os íons estavam em conjunto em solução, a biomassa apresentou maior afinidade pelos íons de $\mathrm{Pb}$, seguida pelo $\mathrm{Zn}$ e por último o $\mathrm{Cd}$. Segundo os autores, a preferência da biomassa pelos íons $\mathrm{Pb}$ pode estar relacionada ao fato de $\mathrm{Pb}$ ter características químicas diferentes, como a de ser o ín mais eletronegativo e tem o maior padrão de redução quando comparado ao Zn e ao Cd. Já no trabalho de Verma, Tewari e Rai (2008) ao utilizar a concentração inicial de $15 \mathrm{mg} \mathrm{L}^{-1}$ de $\mathrm{Cd}$ e $\mathrm{Pb}$ (entre outros metais), a concentração de $\mathrm{Cd}$ na biomassa seca de Eichhornia crassipes foi de 1,72 $\mathrm{mg} \mathrm{g}^{-1}$ e de 0,80 $\mathrm{mg} \mathrm{g}^{-1}$ de Pb. Em uma concentração de $30 \mathrm{mg} \mathrm{L}^{-1}$ a concentração de $\mathrm{Cd}$ e Pb na biomassa foi de 1,98 e 0,95 $\mathrm{mg} \mathrm{g}^{-1}$, respectivamente. Neste estudo, o $\mathrm{Cd}$ foi o metal que apresentou maior 
afinidade aos sítios de ligação da biomassa da planta quando comparado aos outros metais $(\mathrm{Zn}, \mathrm{Pb}$ e $\mathrm{Cu})$.

Com base nestes dados, constata-se que a diferença nas propriedades entre os diversos tipos de materiais utilizados como biossorventes, como sua estrutura, área superficial e grupos funcionais são em parte responsáveis pelas diferenças na sorção de metais. Além das propriedades da biomassa, a composição química da solução também influencia na sorção em razão dos diferentes pHs, temperatura, presença de outros íons e matéria orgânica (MURITHI et al., 2014).

Li et al. (2016) estudaram a concentração de metais no tecido de Eichhornia crassipes que ficaram em contato com água proveniente de um lago contaminado com soluções separadas contaminadas com Cd $\left(10 \mathrm{mg} \mathrm{L}^{-1}\right)$ e $\mathrm{Pb}\left(10 \mathrm{mg} \mathrm{L}^{-1}\right)$. Após seis dias de contato com as soluções as plantas foram removidas e secas. Depois da digestão e leitura das amostras, foram encontrados $1,73 \mathrm{mg} \mathrm{g}^{-1}$ de Cd e 2,70 $\mathrm{mg} \mathrm{g}^{-1}$ de $\mathrm{Pb}$. Comparando com os resultados obtidos no presente trabalho com os de Li et al. (2016) constata-se que a remoção dos metais nos ensaios deles ocorreu em menor tempo.

\section{CONCLUSÕES}

As macrófitas aquáticas Aguapé e Taboa mostraram-se capazes de remover parcialmente os metais $\mathrm{Cd}$ e $\mathrm{Pb}$ de soluções aquosas, tanto no ensaio de biossorção quanto de fitorremediação.

Avaliando os mecanismos envolvidos no processo de biossorção de $\mathrm{Cd}$ e $\mathrm{Pb}$, pode ser observado que o processo é dependente, principalmente, da composição da superfície da biomassa, tanto em relação a sua textura quanto à presença de sítios ativos para que os processos de adsorção ocorram.

De maneira equivalente, o processo de fitorremediação de metais tóxicos está associado à textura da superfície das plantas que, em razão de sua composição, da presença de microrganismos e dos microporos, promovem a adsorção dos metais por mecanismos semelhantes aos da biossorção.

Quando finalmente se compara as tecnologias, em razão da quantidade de metais retidos nos tecidos vegetais, os resultados obtidos pela biossorção apresentam uma maior taxa do que aqueles obtidos pela fitorremediação. Na biossorção, o Aguapé apresentou os valores máximos de $18,8 \mathrm{mg} \mathrm{g}^{-1}(\mathrm{Cd})$ e de $8,6 \mathrm{mg} \mathrm{g}^{-1}(\mathrm{~Pb})$ e a 
Taboa de 15,0 $\mathrm{mg} \mathrm{g}^{-1}(\mathrm{Cd})$ e de 4,6 $\mathrm{mg} \mathrm{g}^{-1}(\mathrm{~Pb})$. Na fitorremediação a concentração no tecido vegetal do Aguapé foi de 3,2 $\mathrm{mg} \mathrm{g}^{-1}(\mathrm{Cd})$ e 4,28 $\mathrm{mg} \mathrm{g}^{-1}(\mathrm{~Pb})$ e de 5,0 $\mathrm{mg} \mathrm{g}^{-1}$ (Cd) e 2,3 $\mathrm{mg} \mathrm{g}^{-1}(\mathrm{~Pb})$ na Taboa.

\section{AGRADECIMENTOS}

Agradecemos à UFABC pelo fornecimento da bolsa de pesquisa e à Central Experimental Multiusuários da UFABC pelos equipamentos disponibilizados e suporte técnico.

\section{REFERÊNCIAS}

ABDEL-GHANI, N. T.; HEGAZY, A. K.; EL-CHAGHABY, G. A. Typha domingensis leaf powder for decontamination of aluminium, iron, zinc and lead: Biosorption kinetics and equilibrium modeling. International Journal of Environmental Science and Technology, v. 6 , n. 2, p. 243-248, 2009.

ALI, H.; KHAN, E.; SAJAD, M. A. Phytoremediation of heavy metals-Concepts and applications. Chemosphere, v. 91, n. 7, p. 869-881, 2013.

APHA - Standard Methods for the Examination of Water and Wastewater. RICE, E. W.; BAIRD, R. B.; EATON, A. D.; CLESCERI, L. S. 22. ed. Washington, USA: American Public Health Association, 2012. várias paginações, il. ISBN 9780875530130.

AZIMI, A.; AZARI, A.; REZAKAZEMI, M.; ANSARPOUR, M. Removal of Heavy Metals from Industrial Wastewaters: A Review. ChemBioEng Reviews, v. 4, n. 1, p. 37-59, 2017.

DAS, S.; GOSWAMI, S.; DAS TALUKDAR, A. Physiological responses of water hyacinth, Eichhornia crassipes (Mart.) solms, to cadmium and its phytoremediation potential. Turkish Journal of Biology, v. 40, n. 1, p. 84-94, 2016.

FAWZY, M.; NASR, M.; ADEL, S.; NAGY, H.; HELMI, S. Environmental approach and artificial intelligence for $\mathrm{Ni}(\mathrm{II})$ and $\mathrm{Cd}(\mathrm{II})$ biosorption from aqueous solution using Typha domingensis biomass. Ecological Engineering, v. 95, p. 743-752, 2016.

FOMINA, M.; GADD, G. M. Biosorption: Current perspectives on concept, definition and application. Bioresource Technology, v. 160, p. 3-14, 2014.

FU, F.; WANG, Q. Removal of heavy metal ions from wastewaters: A review. Journal of Environmental Management, v. 92, n. 3, p. 407-418, 2011.

GOMES, M. A. C.; HAUSER-DAVIS, R. A.; SOUZA, A. N.; VITÓRIA, A. P. Metal phytoremediation: General strategies, genetically modified plants and applications in metal nanoparticle contamination. Ecotoxicology and Environmental Safety, v. 134, p. 133-147, 2016.

HOAGLAND, D.R.; ARNON, D.I. The water-culture method for growing plants without soil. Circular. California Agricultural Experiment Station, v. 347, n. 2, 1950.

IBRAHIM, H. S.; AMMAR, N.S.; SOYLAK, M.; IBRAHIM, M. Removal of Cd(II) and Pb(II) 
from aqueous solution using dried water hyacinth as a biosorbent. Spectrochimica Acta Part A: Molecular and Biomolecular Spectroscopy, v. 96, p. 413-420, 2012.

KUMAR, B.; SMITA, K.; FLORES, L. C. Plant mediated detoxification of mercury and lead. Arabian Journal of Chemistry, v. 10, p. S2335-S2342, 2017

LI, Q.; ZHAN, J.; CHEN, B; MENG, X.; PAN, X. Removal of Pb, Zn, Cu, and Cd by Two Types of Eichhornia crassipes. Environmental Engineering Science, v. 33, n. 2, p. 88-97, 2016.

LIU, W. J.; ZENG. F.X.; JIANG, H.; YU, H.Q. pH-dependent interactions between lead and Typha angustifolia biomass in the biosorption process. Industrial and Engineering Chemistry Research, v. 50, n. 10, p. 5920-5926, 2011.

LYUBENOVA, L.; PONGRAC, P.; VOGEL-MIKUS, K.; MEZEK, G. K.; VAVPETIC, P.; GRLJ, N.; KUMP, P.; NECEMER, M.; REGVAR, M.; PELICON, P.; SCHRÖDER, P. Localization and quantification of $\mathrm{Pb}$ and nutrients in Typha latifolia by micro-PIXE. Metallomics, v. 4, n. 4, p. 333-341, 2012.

MAHAMADI, C.; NHARINGO, T. Competitive adsorption of $\mathrm{Pb}^{+}, \mathrm{Cd}^{+}$and $\mathrm{Zn}^{2+}$ lons onto Eichhornia crassipes in binary and ternary systems. Bioresource Technology, v. 101, n. 3, p. 859-864, 2010.

MAHMOOD, T.; MALIK, S. A.; HUSSAIN, SYED T. Biosorption and Recovery of Heavy Metals from Aqueous Solutions by Eichhornia crassipes (Water Hyacinth) Ash.

BioResources, v. 5, n. 2, p. 1244-1256, 2010.

MUFARREGE, M. M.; HADAD, H. R.; DI LUCA, G. A.; MAINE, M. A. Metal dynamics and tolerance of Typha domingensis exposed to high concentrations of $\mathrm{Cr}, \mathrm{Ni}$ and $\mathrm{Zn}$.

Ecotoxicology and Environmental Safety, v. 105, n. 1, p. 90-96, 2014.

MURITHI, G.; ONINDO, C.O.; WAMBU, E.W.; MUTHAKIA, G.K. Removal of Cadmium(II) Ions from Water by Adsorption using Water Hyacinth (Eichhornia crassipes) Biomass.

BioResources.com, v. 9, n. II, p. 3613-3631, 2014.

OLIVEIRA, J. A.; CAMBRAIA, J.; CANO, M.A.O.; JORDÃO, C.P. Absorção e acúmulo de cádmio e seus efeitos sobre o crescimento relativo de plantas de Aguapé e de Salvínia.

Revista Brasileira de Fisiologia Vegetal, v. 13, n. 3, p. 329-341, 2001.

OLIVEIRA, J. P. V.; PEREIRA, M.P.; DUARTE, V.P.; CORRÊA, F.F.; CASTRO, E.M.; PEREIRA, F.J. Cadmium tolerance of Typha domingensis Pers . (Typhaceae) as related to growth and leaf morphophysiology. Brazilian Journal of Biology, 2018.

PARK, D.; YUN, Y.S.; PARK, J. M. The past, present, and future trends of biosorption. Biotechnology and Bioprocess Engineering, v. 15, n. 1, p. 86-102, 2010.

PRIYA, E. S.; SELVAN, P. S. Water hyacinth (Eichhornia crassipes) - An efficient and economic adsorbent for textile effluent treatment - A review. Arabian Journal of Chemistry, v. 10, p. S3548-S3558, 2017.

REZANIA, S.; PONRAJ, M.; TALAIEKHOZANI, A.; MOHAMAD, S.E.; DIN, M.F.M.; TAIB, S.M.; SABBAGH, F.; SAIRAN, F.M. Perspectives of phytoremediation using water hyacinth for removal of heavy metals, organic and inorganic pollutants in wastewater. Journal of Environmental Management, v. 163, p. 125-133, 2015. 
RODRIGUES, A. C. D.; SANTOS, A.M.; SANTOS, F.S.; PEREIRA, A.C.C.; SOBRINHO, N.M.B.A. Mecanismos de respostas das plantas à poluição por Metais Pesados:

Possibilidade de Uso de Macrófitas para Remediação de Ambientes Aquáticos

Contaminados. Revista Virtual de Quimica, v. 8, n. 1, p. 262-276, 2016.

RZYMSKI, P.; TOMCZYK, K.; RZYMSKI, P.; PONIEDZIALEK, B.; OPALA, T.; WILCZAK, M. Impact of heavy metals on the female reproductive system. Annals of Agricultural and Environmental Medicine, v. 22, n. 2, p. 259-264, 2015.

SARASWAT, S.; RAI, J. P. N. Heavy metal adsorption from aqueous solution using Eichhornia crassipes dead biomass. International Journal of Mineral Processing, v. 94, n. 3-4, p. 203-206, 2010.

SHARAIN-LIEW, Y. L.; JOSEPH, C. G.; HOW, S. E. Biosorption of lead contaminated wastewater using cattails (Typha angustifolia) leaves: Kinetic studies. Journal of the Serbian Chemical Society, v. 76, n. 7, p. 1037-1047, 2011.

SINGH, D.; RICHA, G.; ARCHANA, T. Typha: an Aquatic Macrophyte with Potential Use in Phytoremediation of Wastewater. Asian Journal of Pharmacy and Life Science, v. 1, n. 4, p. 433-438, 2011.

SRIVASTAVA, N. K.; MAJUMDER, C. B. Novel biofiltration methods for the treatment of heavy metals from industrial wastewater. Journal of Hazardous Materials, v. 151, n. 1, p. $1-8,2008$.

STRUNGARU, S. A.; NICOARA, M.; JITAR, O.; PLAVAN, G. Influence of urban activity in modifying water parameters, concentration and uptake of heavy metals in Typha latifolia $L$. into a river that crosses an industrial city. Journal of Environmental Health Science and Engineering, v. 13, n. 1, p. 1-11, 2015.

SYUKOR, A. R. A.; SULAIMAN, S.; SIDDIQUE, M.N.I.; ZULARISAM, A.W.; SAID, M.I.M. Integration of phytogreen for heavy metal removal from wastewater. Journal of Cleaner Production, v. 112, p. 3124-3131, 2016.

TAVARES, S. R. L.; OLIVEIRA, S. A.; SALGADO, C. M. Avaliação de espécies vegetais na fitorremediação de solos contaminados por metais pesados. Holos, v. 5, p. 80-97, 2013.

VERMA, V. K.; TEWARI, S.; RAI, J. P. N. lon exchange during heavy metal bio-sorption from aqueous solution by dried biomass of macrophytes. Bioresource Technology, v. 99, p. 1932-1938, 2008.

WENZL, T.; JOHANNES, H.; SCHAECHTELE, A.; ROBOUCH, P.; STROKA, J. Guidance Document on the Estimation of LOD and LOQ for Measurements in the Field of Contaminants in Feed and Food. Publications Office of the European Union: Luxemburg, 2016.

ZHANG, F.; WANG, X.; YIN, D.; PENG, B.; TAN, C.; LIU, Y.; TAN, X.; WU, S. Efficiency and mechanisms of $\mathrm{Cd}$ removal from aqueous solution by biochar derived from water hyacinth (Eichhornia crassipes). Journal of Environmental Management, v. 153, p. 68-73, 2015.

ZHENG, J. C.; LIU. H.Q.; FENG, H.M.; LI, W.W.; LAM, M.H.W.; LAM, P.K.S.; YU, H.Q. Competitive sorption of heavy metals by water hyacinth roots. Environmental Pollution, v. 219, p. 837-845, 2016. 